\title{
Transitory Environmental Threat Alters Sexually Dimorphic Mate Preferences and Sexual Strategy
}

\author{
Simon D. Reeve ${ }^{1} \cdot$ Kristine M. Kelly $^{2} \cdot$ Lisa L. M. Welling ${ }^{1}$
}

Published online: 20 January 2016

(C) Springer International Publishing 2016

\begin{abstract}
The Environmental Security Hypothesis (ESH) proposes that when the environment is less secure, people will show greater preference for mates with survival-promoting traits (Pettijohn and Jungeberg in Personality and Social Psychology Bulletin, 30(9), 1186-1197, 2004). In this study, we manipulated perceived environmental security and measured preference for different body and face characteristics as well as attitudes toward long-term (LTM) and short-term mating (STM) strategies. Participants $(N=100)$ received a cover story designed to lead experimental, but not control, participants to believe they would be required to handle a poisonous snake. Participants then completed a measure of sociosexual orientation and selected the three opposite-sex face and body types that they found most attractive from image matrices depicting physical characteristics varying systematically across body and face shape. Female bodies varied in body fat and waist-to-hip ratio, and male bodies varied in muscle mass and waist-to-chest ratio. Face stimuli varied in masculine-feminine facial shape and masculine-feminine facial coloration. Results indicated that, compared to controls, men in the environmental-threat condition showed a preference for higher body fat, and women in the environmental-threat condition showed a preference for higher muscle mass and more masculine faces. These women also showed a more positive attitude toward STM, but not LTM. In line with the ESH, our
\end{abstract}

Lisa L. M. Welling

welling@oakland.edu

1 Department of Psychology, Oakland University, 2200 N. Squirrel Road, Rochester, MI 48309, USA

2 Department of Psychology, Western Illinois University, 1 University Circle, Macomb, IL 61455, USA findings predominantly support a context-specific pattern of mate preference and sexual strategies.

Keywords Environmental security hypothesis $\cdot$ Mate preference $\cdot$ Sexual dimorphism $\cdot$ Sexual strategies $\cdot$ Fear . Threat

\section{Introduction}

Human mate preferences are impacted by environmental cues. Cross-cultural research has shown that women's preference for masculinity can be negatively predicted from a composite health index score (derived from World Health Organization statistics; DeBruine et al. 2010, 2011). Indeed, a trait or quality in a mate that provides an adaptive advantage in one set of circumstances may not provide the same advantage under a different set of circumstances or the advantage may be less relevant compared to other factors. Therefore, in order to maximize reproductive success, an individual's mate preferences should take into account the demands of their environment and thus favor mates that are best suited to increasing the individual's reproductive success under specific conditions by providing an advantage to either the individual themselves or their resultant offspring. For example, a greater preference for body fat in a resource-scarce environment could be adaptive as it suggests that the individual has greater access to resources or, in the case of females, can better sustain a pregnancy and nourish infants. Similarly, a greater preference for dominance, strength, and/or muscle in a volatile environment could be adaptive as it may suggest that an individual has a greater ability to protect their mate and their offspring and/or provide the offspring with genes to likewise develop such an advantage. 
Given that an individual must first survive in order to reproduce, traits more directly related to helping an individual or their offspring survive should become more relevant predictors for potential reproductive success in a particularly unaccommodating and hazardous environment. The influence of environmental threat on mate preference forms the premise of the Environmental Security Hypothesis (ESH; Pettijohn and Tesser 1999), which proposes that an individual's mate preferences may depend on how secure or insecure they feel in their surroundings. Specifically, the ESH suggests that when people perceive their environment to be harsher, whether from social or economic conditions, they will show an increased preference for traits that suggest maturity, which is associated with the ability to handle and/or alleviate threat (Pettijohn et al. 2009). Put another way, when individuals experience environmental threat, a greater attraction to traits more associated with surviving and thriving may become more adaptive.

In line with the ESH, Pettijohn and Jungeberg (2004) looked at the characteristics of playboy playmates from 1960 to 2000 and found that when social and economic conditions were harsher, the Playboy Playmate of the year was more likely to be older, heavier, and taller with a larger waist, smaller eyes, a larger waist-to-hip ratio, a smaller bust relative to the waist, and a higher body mass index. Likewise, when social and economic conditions were better, the Playboy Playmate of the year was more likely to be younger, lighter, and shorter, with a smaller waist, larger eyes, a more feminine waist-to-hip ratio, and a larger bust-to-waist ratio. Similarly, better economic conditions predict a greater prevalence of neotenous facial features (e.g., larger eyes, rounder cheeks, and smaller chins) among popular American movie actresses (Pettijohn and Tesser 1999). Given that movie actresses are typically popular in part due to their physical attractiveness, the authors conclude that their results are likely to reflect population-wide preferences for these characteristics. Although there was no effect found for economic conditions and any facial features of popular American movie actors in a comparable study (Pettijohn and Tesser 2003), there is some cultural support for a greater preference for more masculine facial traits within both men and women in less prosperous environments. Perrett et al. (1998) found no significant population differences in masculinity preferences between economically similar British and Japanese samples, whereas Penton-Voak et al. (2004) found that British men and women preferred more feminine opposite-sex faces than comparatively disadvantaged Jamaican men and women. These authors propose that their findings may be attributable to a greater amount of parasites, medical care being less common (historically and currently), and parental investment being less pronounced in Jamaica compared to Britain, whereas Britain and Japan differ less in these ways. Research on experimentally induced and naturally occurring cues of environmental threat suggests that mate preferences can also be temporarily altered in ways consistent with the ESH. Pettijohn et al. (2009) (see also Nelson and Morrison 2005) investigated hunger as a resource scarcity cue in two field studies in a university dining hall, using participants that had not yet eaten or had just eaten. They found that hungry male participants reported a preferred ideal romantic partner that was heavier, shorter, and older than the preferred partner described by satiated males, whereas hungry female participants showed greater preference for a mature personality cluster (strong, mature, independent, competent) than non-mature (warm, naive, kind, agreeable) compared to satiated women. Pettijohn and Tesser (2005) found that when male participants were induced into higher state of anxiety via threat of a painful electric shock, they were more likely to prefer to work with a member of the opposite sex with smaller eyes (i.e., less neotenous) compared to participants that were in a minimal state of anxiety. Nelson and Morrison (2005) found that when male, but not female, participants were induced into a financially dissatisfied state, they reported preferring a heavier mate than did financially satisfied men. Sacco et al. (2011) showed that priming or inducing feelings of social threat (i.e., rejection) led women to show a greater preference for muscularity (i.e., preferred more muscular arms). Snyder et al. (2011) found that women's fear of crime predicts mate preference for dominance and physically formidability. Altogether, this research lends support to the ESH by demonstrating how mate preferences can be flexible to environmental cues.

As well as a mate preference shift, an insecure environment may also result in a reproductive strategy shift. In a more threatening environment, future survival is less certain so it may also be adaptive for an individual to speed up their reproductive efforts to reproduce sooner. In line with Life History theory, immediate reproductive effort becomes more adaptive than effort toward future reproductive success (somatic effort) in less secure environments given the higher risk that future reproductive opportunity would be unrealized should they die. Indeed, Griskevicius et al. (2011) found that both current and childhood socioeconomic status were predictive of a desire to reproduce earlier or younger. After priming a social rejection threat, Sacco et al. (2011) found increased short-term mating interest among women. In five studies priming pathogen concerns, Hill et al. (2015) found that women, but not men, with a greater dispositional vulnerability to illness show an increased desire to mate with more novel partners. Sacco et al. interpreted this finding as an attempt to increase the likelihood of producing healthy, resistant offspring despite the increased disease risk of mating with many partners, highlighting that adaptive context-dependent mating shifts can be more geared toward future offspring survival over the individual's own survival.

Although previous research on the ESH has largely focused on physical cues and/or personality characteristics that suggest 
maturity, such traits are also indicative of physical masculinity/femininity. Indeed, Boothroyd et al. (2005) have suggested that a preference for masculinity in men is highly related to a preference for older males and femininity in females has been suggested to be somewhat synonymous to a preference for youth (Jones 1995). Although masculinity may increase and femininity decrease with age, such characteristics are enormously influenced by sex hormones, particularly estrogen and testosterone (e.g., Frayer and Wolpoff 1985). Certainly, there seems to be a relationship between sex hormones and environmental security: Research has shown that estrogen levels fall in response to increased physical activity and stress (Jasieńska and Ellison 1998; Jasienska et al. 2006), whereas testosterone and other androgens have been shown to rise in response to stressors, endurance exercise, and competition (Bateup et al. 2002; Copeland et al. 2002; Keizer et al. 1987; Kuoppasalmi et al. 1976; Volek et al. 1997; Webb et al. 1984). Thus, the present study aims to expand on the existing research by investigating the effect of an environmental insecurity cue on mate preference with a greater theoretical focus on sexual dimorphic aspects of the face and body.

\section{Sexual Dimorphism of the Body and Face}

In line with evolutionary theory, sexual dimorphism present in modern humans has likely evolved in response to selective pressures (Trivers 1972; Symons 1979): Women biologically invest more in offspring (e.g., breast feeding and gestation) than men, which leads them to be typically more selective overall in the mating process. On the other hand, due to their minimal biological commitment, men can maximize their reproductive success by acquiring sexual access to many women. Consequentially, men compete with other men for access to females. Competition results in an advantage for stronger, larger, and more socially and physically dominant men, and such men would experience more reproductive success when such qualities can be capitalized on. Likewise, due to their biological commitment in the reproductive process, there have been strong selective pressures acting on women to promote effective child conception, gestation, nourishing, and birthing. Ancestrally, women with qualities that promote this process, such as fertility, fat reserves, and hips to allow the safe birth of well-developed offspring, will have experienced greater reproductive success than others.

There is a significant sexual dimorphism in body composition characterized by a substantially higher amount of body fat and a substantially lower amount of muscle mass among women (Folland and Williams 2007; Kirchengast 2010). Physiologically, sex differences in body composition are caused by sex typical differences in sex hormone secretion (Gatford et al. 1998; Lavranos et al. 2006; Rosenbaum and Leibel 1999) and lipid metabolism (Mittendorfer 2005). Although sexual dimorphism in body composition exists to a small extent at birth, during the pubertal years this dimorphism increases greatly (Loomba-Albrecht and Styne 2009; Rogol et al. 2002) and by adulthood there is a substantial difference in body composition between men and women (Wells 2007, 2012). There are also significant differences in body shape characterized by a greater discrepancy between the measurements of the waist and hips (i.e., waist-to-hip ratio [WHR]) of women relative to men and a greater differential between the measurements of the chest/shoulders and hips/waist ${ }^{1}$ (waist-to-chest ratio [WCR] or shoulder-hipratio[SHR], respectively) of men relative to women (Tanner 1981). As with body composition, these sex differences in body shape are likewise caused by sex typical differences in testosterone and estrogen levels (Evans 1972; Jasienska et al. 2004; Kasperk et al. 1997), which develop most dramatically during puberty via the growth of the skeleton and the distribution of fat and muscle (Biro et al. 2003; He et al. 2004; Kasperk et al. 1997; Price et al. 1998; Refubbe-Scrieve 1988; Reubinoff et al. 1995).

In line with the immunocompetence handicap hypothesis (Folstad and Karter 1992), masculine traits in men are likely an honest indicator of health as testosterone actively suppresses the immune system so that only healthy males can afford to develop prominent masculine traits. Additionally, effort allocated to developing these attributes increases energy demands and metabolism (Manning et al. 1997). Either way, traits produced by high levels of testosterone could reasonably be considered cues to good survivability because they indicate that the male can afford to generate these costly traits. Indeed, Johnston et al. (2001) reported that women preferred a male face that was more masculine than average, and masculinity is associated with dominance (Perrett et al. 1998). For female faces, facial femininity is related to fertility and estrogen levels (Johnston 2000; Law Smith et al. 2006), indicating that a preference for feminine faces could be best interpreted as a preference for a more fertile female. Indeed, Johnston (2000) suggests that beautiful female faces actually vary from the average via augmented femininity. Facial sexual dimorphism occurs not only in the shape of the face but also in the coloration of the face (Rowland and Perrett 1995): Compared to men, women tend to have darker eyes and lips relative to the rest of their face. Indeed, Russell (2003) manipulated male and female faces by either lightening the eyes and lips (decreasing contrast) or darkening the eyes and lips (increasing contrast) while keeping the rest of the face constant. This author found that female faces with greater facial contrast

\footnotetext{
${ }^{1}$ Given that the average and preferred male ratio between the waist and hips is typically close to 1 (e.g., mean WHR of between .87 and .99 across 19 populations; Molarius et al. 1999; e.g., preferred male WHR of .9; Singh 1995), these two methods of measuring masculine sexual dimorphic body shape are typically approximately equivalent and will be discussed interchangeably.
} 
were rated more attractive, whereas the opposite was found with the male faces.

\section{The Present Study}

The present study aims to investigate the effect of an environmental insecurity cue on preference for sexually dimorphic aspects of the face and body. Although previous research has used environmental threat cues such as anticipated electric shocks, hunger, and priming toward a financially dissatisfied mindset (Nelson and Morrison 2005; Pettijohn et al. 2009; Pettijohn and Tesser 2005), here we use the novel environmental threat cue of handling a poisonous snake. There is evidence to suggests that a fear (or at least wariness) of snakes is instinctual, automatic, and hardwired into the most primal parts of the brain (Isbell 2006; Öhman and Mineka 2001; Soares 2012; see also Shibasaki and Kawai 2009 for similar evidence among nonhuman primates), making this a particularly salient threat cue. Whereas previous research on temporal cues of environmental threat has only considered preference for total body weight reported numerically in units of weight (typically in imperial pounds; Nelson and Morrison 2005; Pettijohn et al. 2009), the present study will use matrices of body and face types that vary systematically across sexually dimorphic dimensions. It is predicted that an environmental threat cue will lead to an increased preference for cues to survivability over cues to fertility. Specifically, it is predicted that men who are exposed to an environmental threat cue will show a greater preference for women with a greater level of body fat, higher WHR, a lower preference for feminine face shape, and lower facial contrast (i.e., lighter eyes and lips relative to skin tone). Likewise, it is predicted that women who are exposed to an environmental threat cue will show a greater preference for men with a greater level of muscle mass and a lower WSR reflecting an increased preference for immediate survivability (despite the potential reduction in longterm parental investment also associated with these traits; Archer 2006; Booth and Dabbs 1993; McIntyre et al. 2006; Peters et al. 2008), as well as a greater preference for masculine male faces and lower facial contrast.

\section{Method}

\section{Participants}

A total of 103 participants were recruited from a large public university in the USA in return for course credit. Only heterosexuals were recruited given that the study concerns heterosexual mate choices. Three participants were removed from the data set for reporting suspicion (see below), leaving a total of 100 participants (64 female; age, $M=20.04$ years, $S D=1.61$, range $=18-26$; ethnicity, $65 \%$ Caucasian, $22 \%$
Black, $9 \%$ Hispanic, $4 \%$ other). Informed consent was obtained from all participants, and all participants reaffirmed their consent to have their data included after debriefing.

\section{Stimuli}

Participants were presented with two picture matrices depicting physical aspects of a person of the opposite sex. The matrices contained 25 opposite sex body types (see Fig. 1a, b) and 25 opposite sex face types (see Fig. 2a, b). Each set of stimuli varied on two dimensions through five increments (i.e., a $5 \times 5$ matrix): Male body stimuli varied on WCR and muscle mass; female body stimuli varied on WHR and body fat; male and female face stimuli varied on shape (more masculine to more feminine) and coloration (more feminine higher contrast to more masculine lower contrast).

Body stimuli were developed using the open source 3D modeling software Make Human (available from www. makehuman.org). The base male and female figures provided with the software were manipulated via two dimensions by adjusting the appropriate morphing dials. For body composition, the devoted full-body "Muscle" morph was applied in $20 \%$ increments for male figures and the full-body "Fat" morph was applied in $20 \%$ increments for female figures. For body shape, the 2D measurements of the hip (for female figures) or chest (for male figures) were taken and compared to the narrowest point of the waist. Adjustments were then made using the "Hip Circumference" dial or "Chest Width" dial until 2D WHR or WCR varied by increments of . 10.

Face stimuli were developed using 3D modeling software FaceGen $^{2}$ (available from www.facegen.com). The base male and female faces provided by the software were manipulated via two dimensions by adjusting the appropriate morphing dials. For facial shape, the "Gender" morph was applied in $20 \%$ increments from the middle toward the "very male" end of the range for male faces and toward the "very female" end of the range for female faces. For facial coloration, the "Lips-Light/dark" and "Eyes (whole)-Light/ dark" morph was applied in $20 \%$ increments across the available range to increase the facial contrast.

\section{Procedure}

To induce a temporary feeling of environmental insecurity, participants in the experimental condition $(n=52,32$ female $)$ were led to believe that they would be required to handle a

\footnotetext{
${ }^{2}$ FaceGen software was built upon the statistical modeling of a sample of 300 real faces varying in gender and ethnicity. Therefore, the morphs are based on real facial dimensions. The morph we applied drew from sex differences in facial structure established from this sample and so arguably represents a reasonable section of the masculine-feminine continuum.
} 
a

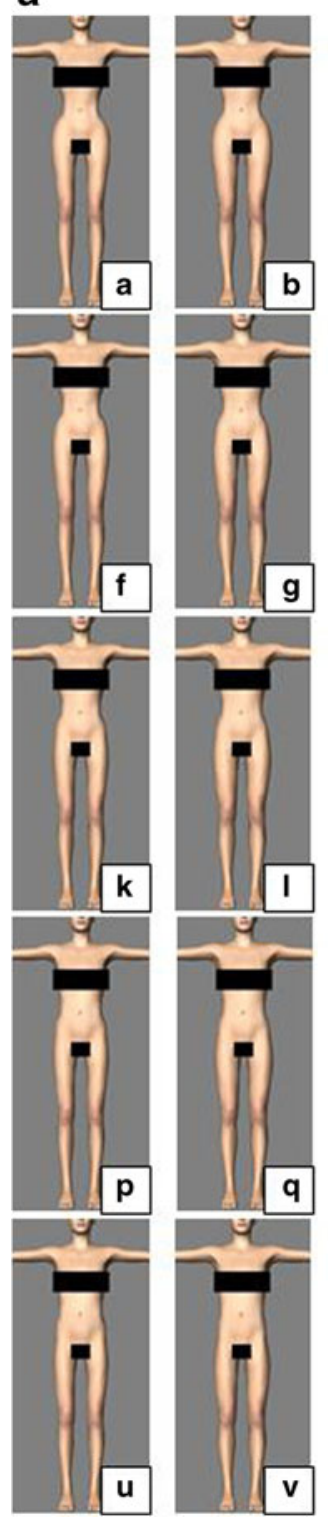

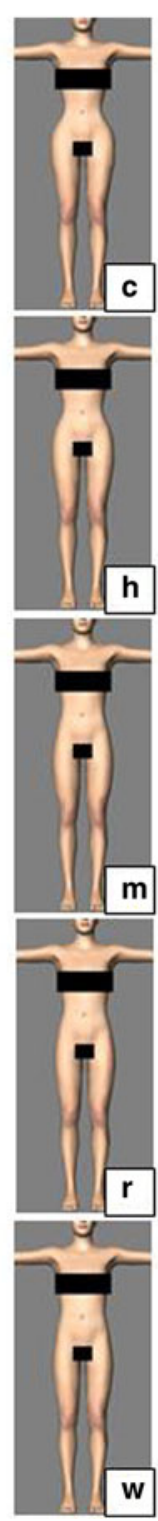
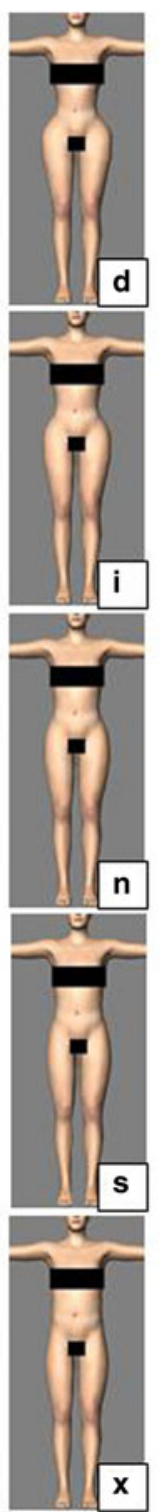
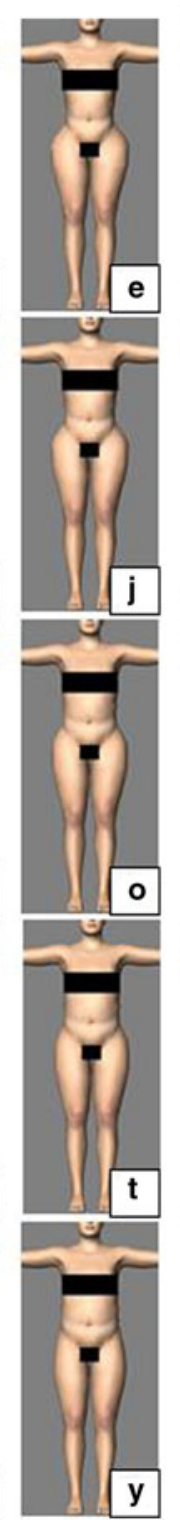

b
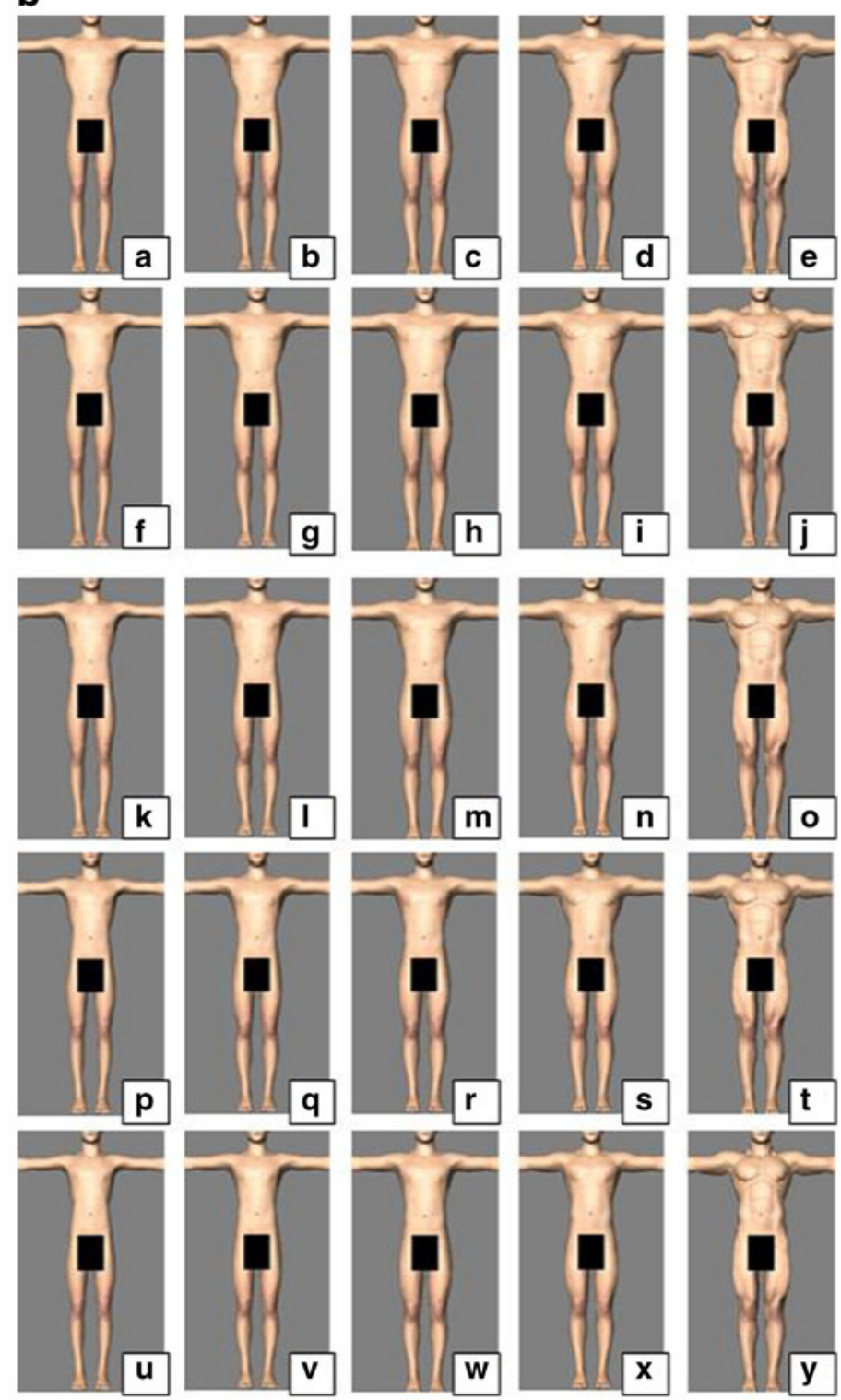

Fig. 1 a Female body type stimuli presented to male participants which vary in waist-to-hip ratio (by row) and body fat (by column). Note: Images were presented to participants in a randomly generated ordernot ordered systematically by dimensions and increments as presented

here. b Male body type stimuli presented to female participants which vary in waist-to-shoulder ratio (by row) and muscle mass (by column). Images were presented to participants in a randomly generated order

snake so that the researchers could investigate a (fictitious) pheromone response hormone - obtained and measured from a saliva swab - and how differences in levels are related to different evolved preferences. For experimental participants, a metal research animal box (typically used for housing and moving laboratory rats) containing bedding material and a realistic plastic snake was presented to corroborate this aspect of the cover story. This mock habitat was on the next desk in the lab, approximately $5 \mathrm{ft}$ in front of the participant, to prevent closer inspection from compromising the cover story, and was only visible for a short time. Participants in the control condition were told the same cover story except that the researchers omitted mention of the snake (i.e., they were only read the first two sentences of the script below). For both control and experimental participants, a jar of cotton swabs and a box of plastic gloves were present to corroborate the saliva sample element of the cover story.

The experimental script read as follows (elements in square brackets denote non-verbalized instructions/actions by researcher):

We are investigating a pheromone response hormone and how differences in levels of it are related to different evolved preferences. Essentially, we would like you to 
Fig. 2 a Female face stimuli presented to male participants which vary in masculinefeminine facial coloration contrast (by columns) and masculinefeminine facial shape (by rows). Images were presented to participants in a randomly generated order. b Male face stimuli presented to female participants which vary in masculine-feminine facial coloration contrast (by columns) and masculine-feminine facial shape (by rows). Images were presented to participants in a randomly generated order a
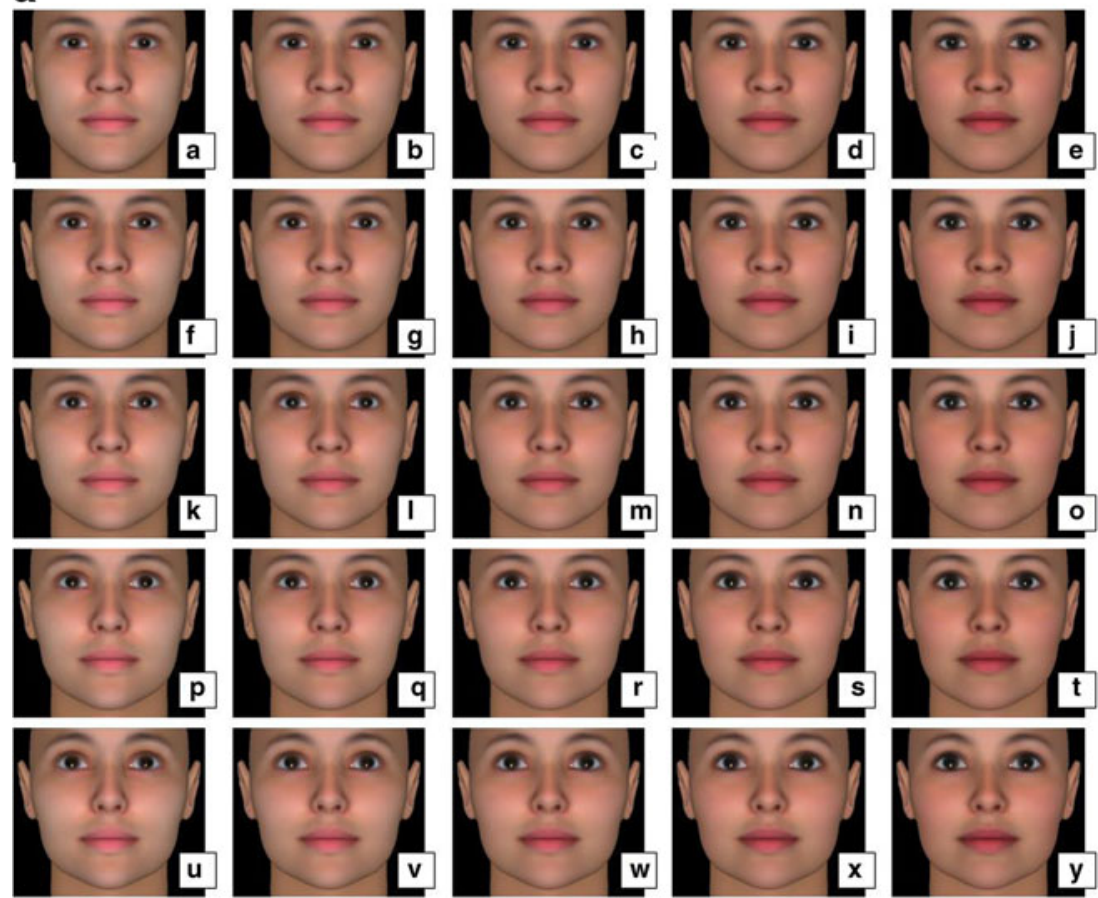

b
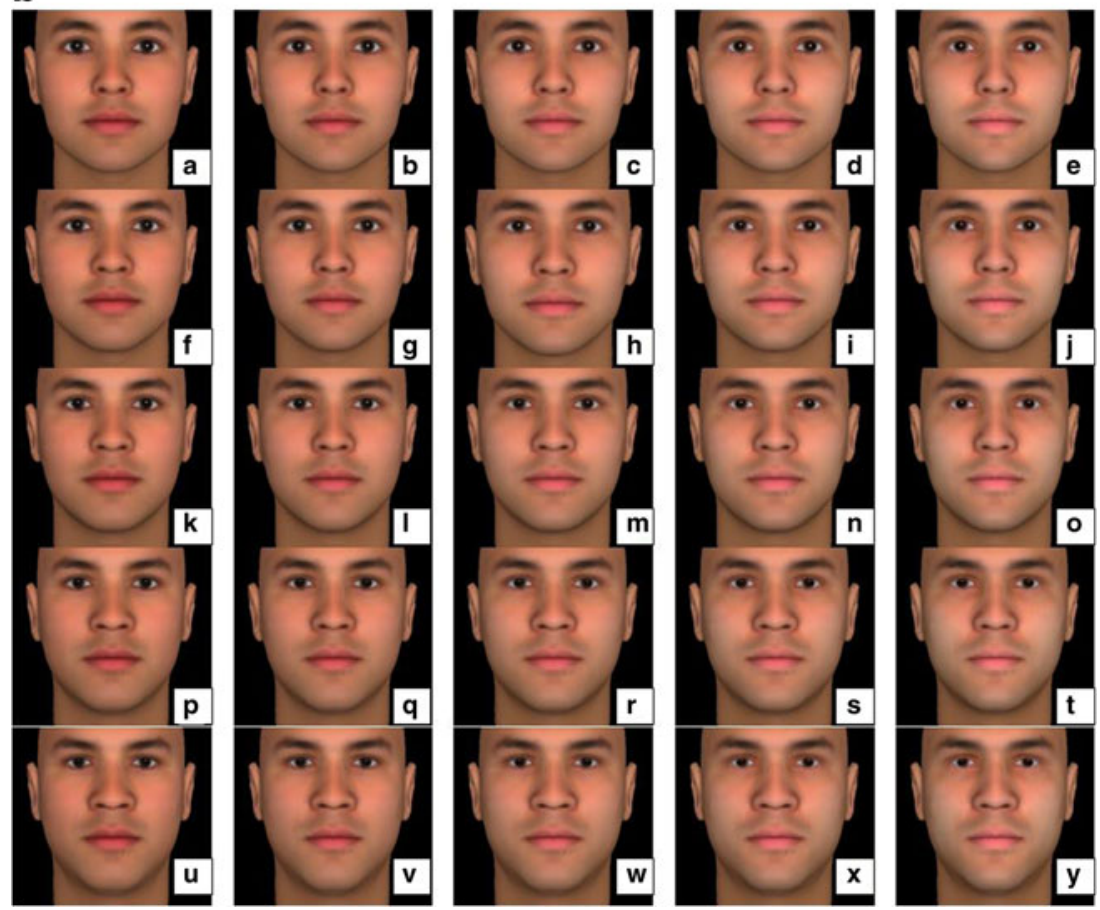

fill out a few questionnaires on a variety of preferences, behaviors, and attitudes and then we'll take a saliva swab [indicate jar of cotton swabs] to get a sample for us to analyze. This hormone is released when the body encounters unusual or unfamiliar stimuli. So, to trigger release of this hormone, we're going to need you to handle this snake [indicate box/habitat $]$ for 5 minutes before we take the saliva swab. This species of snake is poisonous, but not deadly. We have the anti-venom on hand in case you do get bitten, but that's very unlikely as he's tame. Also, if the snake starts to get agitated or angry we'll stop early.

Next, participants completed a basic demographic survey (age, ethnicity, and relationship status). Participants were then shown the picture matrices depicting a person of the opposite 
sex (described above) and were instructed to select the three images that they found most attractive from each matrix. Then, participants were asked to complete a series of questionnaires. We used two attitudinal aspects of sociosexual orientation (Short-Term Mating Orientation and Long-Term Mating Orientation) and one behavioral measure (Previous Sexual Behavior) using items from the Multi-dimensional Model of Sociosexual Orientation (MMSO; Jackson and Kirkpatrick 2007). Short-Term Mating Orientation (STMO) consisted of ten items (e.g., "I can easily imagine myself being comfortable and enjoying 'casual' sex with different partners") and Long-Term Mating Orientation (LTMO) consisted of seven items (e.g., "I am interested in maintaining a longterm relationship with someone special"). Questions were answered using a seven-point Likert scale (anchors: $1=$ strongly disagree, $7=$ strongly agree) and measures achieved a Cronbach' alpha of .95 and .82, respectively. The Previous Sexual Behavior measure consisted of three items gauging total number of sexual partners (e.g., "During your entire life, how many different partners of the opposite sex have you had sexual intercourse with?") reported freely as numeric quantities and achieved a Cronbach' alpha of 69.

Participants also completed the 60-item Positive and Negative Affect Scale (PANAS-X; Watson, and Clark 1999). The entire inventory was included to help disguise the true purpose of the study. However, the subscale of interest for the manipulation check was the six-item Fear subscale. Responses were reported on a five-point scale (anchors: $1=$ very slightly or not at all, $5=$ extremely) and achieved a Cronbach' alpha of .85 . We also included the Big Five Inventory (John and Srivastava 1999) to disguise the true purpose of the study, but these responses were not analyzed. Finally, participants were verbally screened for suspicion using a funneling approach ("Do you have any questions about the study so far?", "Does anything seem weird or suspicious about the study so far?" and "What's your understanding of true purpose of the study?" e.g., Bargh and Chartrand 2000; Ruys and Stapel 2008). Any response suggesting that a participant was skeptical of the cover story was noted and their data were discarded. Immediately after these questions, participants were fully debriefed on the true purpose of the study.

\section{Results}

\section{Manipulation Check}

To assess whether the experimental manipulation was successful, a 2 (control vs. experimental condition) $\times 2$ (male vs. female) factorial ANOVA was conducted. A significant main effect of condition was revealed, $F(1,95)=20.60, p<.01$, $\eta_{p}{ }^{2}=.18$, with participants in the control condition reporting significantly less fear $(M=1.44 ; S D=.44)$ than those in the experimental condition $(M=2.07 ; S D=.80)$. There was no significant main effect of participant sex, $F(1,95)=.90$, $p=.36, \eta_{p}{ }^{2}=.01$, nor a significant interaction, $F(1,95)=.25$, $p=.595, \eta_{p}{ }^{2}<.01$.

\section{Preferences for Physical Qualities of the Face and Body}

ANCOVAs were conducted to assess the effect of experimental condition on various preferences for physical qualities of the face and body. ANCOVAs were used to statistically control for the second dimension depicted in each of the image matrices (e.g., when selecting an image from the face matrices, their choice relates to both a degree of masculine-feminine facial shape and also a degree of masculine-feminine facial coloration). Standard ANOVAs yield an identical pattern of significant results as found using ANCOVAs.

Face Preferences For male participants (Fig. 3), there was no significant effect of experimental condition on preference for facial shape while controlling for preference for facial coloration, $F(1,33)=.93, p=.34, \eta_{p}{ }^{2}=.03$. There was also no significant effect of experimental condition on preference for facial coloration while controlling for preference for facial shape, $F(1,33)=.12, p=.73, \eta_{p}^{2}<.01$.

For female participants (Fig. 4), there was a significant effect of experimental condition on preference for face shape while controlling for preference for facial coloration, $F(1$, $61)=5.89, p=.02, \eta_{p}{ }^{2}=.09$, with participants in the experimental condition selecting male face types that were significantly more masculine in shape $(M=3.10 ; S D=.99)$ than those in the control condition $(M=2.49 ; S D=.80)$. Facial coloration was not a significant covariate, $F(1,61)=.25, p=.62$, $\eta_{p}{ }^{2}<.01$. There was also a significant effect of experimental condition on preference for facial coloration while controlling for preference for facial shape, $F(1,61)=4.83, p=.03$, $\eta_{p}{ }^{2}=.07$, with participants in the experimental condition selecting male faces that were significantly more masculine in coloration (i.e., faces of lower contrast; $M=3.09 ; S D=.77$ ) than those in the control condition $(M=2.64 ; S D=.75)$. Facial shape was not a significant covariate, $F(1,61)=.25, p=.62$, $\eta_{p}{ }^{2}<.01$.

Body Preferences For male participants (Fig. 3), there was a significant effect of experimental condition on preference for body fat while controlling for preference for WHR, $F(1$, $33)=7.04, p=.01, \eta_{p}{ }^{2}=.18$, with participants in the experimental condition selecting female body types that were significantly higher in body fat $(M=3.42 ; S D=.88)$ than those in the control condition $(M=2.75 ; S D=.51)$. WHR was not a significant covariate, $F(1,33)=.94, p=.34, \eta_{p}{ }^{2}=.03$. There was no significant effect of experimental condition on 


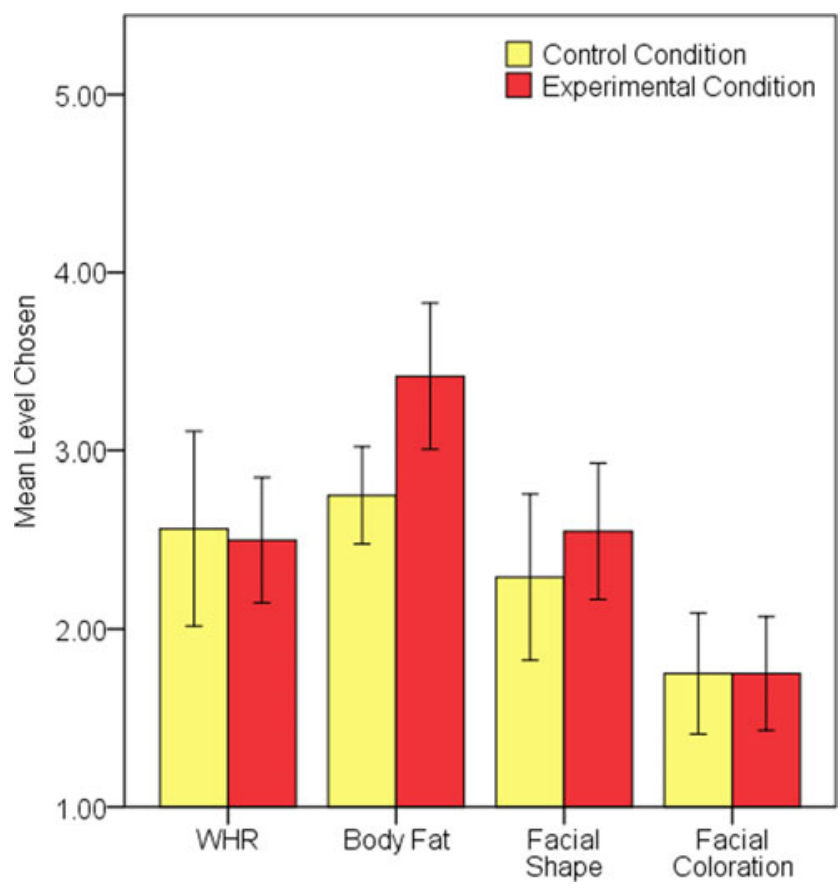

Fig. 3 Mean level of each physical attribute chosen by control and experimental condition male participants from the respective face and body image matrices. Error bars represent $95 \%$ CI

preference for WHR while controlling for preference for body fat, $F(1,33)=.05, p=.83, \eta_{p}{ }^{2}=<.01$.

For female participants (Fig. 4), there was a significant effect of experimental condition on preference for muscle mass while controlling for preference for WCR, $F(1$,

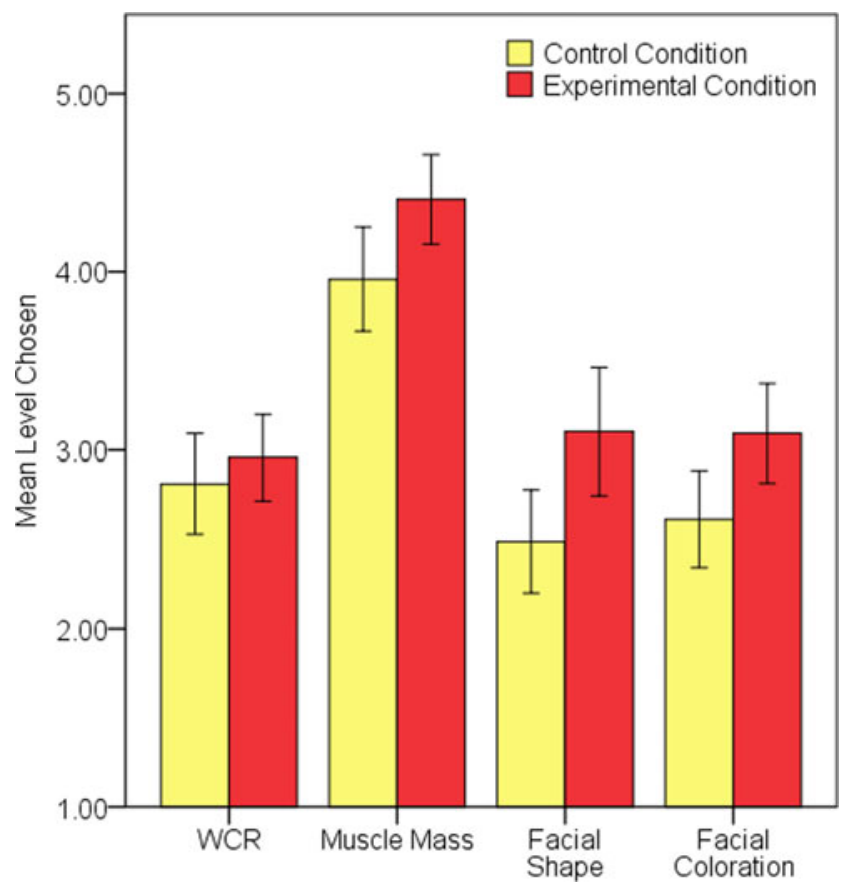

Fig. 4 Mean level of each physical attribute chosen by control and experimental condition female participants from the respective face and body image matrices. Error bars represent $95 \% \mathrm{CI}$
$61)=5.39, p=.02, \eta_{p}{ }^{2}=.08$, with participants in the experimental condition selecting male body types that were significantly higher in muscle mass $(M=4.40 ; S D=.70)$ than those in the control condition $(M=3.96 ; S D=.81)$. WCR was not a significant covariate, $F(1,61)=.03, p=.87, \eta_{p}{ }^{2}<.01$. There was no significant effect of experimental condition on preference for WCR while controlling for preference for muscle mass, $F(1,61)=.51, p=.48, \eta_{p}^{2}=.01$.

Sexual Strategy The effect of condition on attitudes to shortterm and long-term mating scenarios was analyzed using ANOVA. For male participants, there was no significant effect of experimental condition on attitude for STMO, $F(1$, $34)=.15, p=.70, \eta_{p}{ }^{2}=<.01$, nor on attitude for LTMO $F(1$, 34) $=1.27, p=.27, \eta_{p}{ }^{2}=.04$.

For female participants, there was a significant effect of experimental condition on attitude for STMO, $F(1$, $62)=5.06, p=.03, \eta_{p}{ }^{2}=.08$, with participants in the experimental condition reporting higher ratings for STMO $(M=3.44 ; S D=.1 .51)$ than those in the control condition $(M=2.58 ; S D=1.55)$. However, there was no significant effect of experimental condition on attitude for LTMO, $F(1$, $62)=2.71, p=.11, \eta_{p}{ }^{2}=.04$. In addition, there was no significant difference between conditions in reported Previous Sexual Behavior for men $F(1,34)=2.15, p=.15, \eta_{p}{ }^{2}=.06$, nor women, $F(1,62)=.10, p=.76, \eta_{p}{ }^{2}<.01$, suggesting that random assignment was successful and that there were no preexisting group differences in indicators of sexual strategy.

Post Hoc Analysis To test for the possibility of a dynamic relationship for women between significant indicators of sexual strategy (i.e., STMO) and significant indicators of mate preference (i.e., facial shape, facial coloration, and muscle mass), a combination of ANCOVAs was conducted around these variables: Three analyses with STMO as the dependent variable with (1) muscle mass included as a covariate, (2) facial shape included as a covariate, and (3) facial coloration included as a covariate, and three analyses with STMO included as a covariate on (1) muscle mass as the dependent variable, (2) facial shape as the dependent variable, and (3) facial coloration as the dependent variable. However, the effect of condition on STMO remained significant when muscle mass $\left(F[1,61]=5.19, p=.03, \eta_{p}{ }^{2}=.08\right)$ or facial shape $(F[1$, $\left.61]=4.22, p=.044, \eta_{p}{ }^{2}=.07\right)$ were included as a covariate and remained marginally significant when facial coloration was included as a covariate $(F[1,61]=3.35, p=.07$, $\left.\eta_{p}{ }^{2}=.05\right)$. Likewise, the effect of condition on muscle mass $\left(F[1,61]=5.74, p=.02, \eta_{p}{ }^{2}=.09\right)$, facial shape $(F[1$, $\left.61]=6.51, p=.01, \eta_{p}{ }^{2}=.10\right)$, and facial coloration $(F[1$, $\left.61]=4.56, p=.04, \eta_{p}{ }^{2}=.07\right)$ remained significant when STMO was included as a covariate in each case. Taken together, these analyses suggest that the effects found for STMO are 
predominantly independent of the effects found for the significant mate preference variables and vice versa.

\section{Discussion}

Results showed a significant effect of environmental security on male preference for female body fat, whereby participants who were led to believe that they would be in contact with a poisonous snake selected female body types that were significantly higher in body fat than those without this prime. This finding is highly consistent with previous research on the ESH and context-dependent mate preferences (e.g., Nelson and Morrison 2005; Pettijohn et al. 2009; Swami and Tovée 2006, 2012) and crosscultural findings comparing populations from differing socioeconomic conditions (e.g., Swami 2015; Swami et al. 2007; Swami and Tovée 2005). However, whereas previous research has focused on cues of resource scarcity (i.e., hunger, wealth, and financial satisfaction; Nelson and Morrison 2005; Pettijohn et al. 2009; Swami and Tovée 2006) or psychological stress (Swami and Tovée 2012), these findings would suggest that a safety threat has a comparable effect. From an evolutionary perspective, a greater preference for a female with more body fat in an environment where safety is less certain would be adaptive as this would provide her with a greater reserve of energy from which she could draw on to survive, gestate, and nourish infants should the male fail to provide sufficiently, become separated from her (unintentionally or intentionally), or even die due to such threats. In addition, the null finding for differences in WHR preference suggest that it may be predominantly body fat amount preference that is influenced by threat rather than a gynoid fat distribution pattern (i.e., more fat deposited on the hips, thighs, and buttocks; Price et al. 1998).

Conversely, the present study failed to replicate Pettijohn and Tesser's (2005) finding that a harm threat biased men to prefer more mature looking women (and thus more masculine looking women; Boothroyd et al. 2005), insofar as men under the threat condition in the present study were no different from controls in their female face preference. This inconsistency could arise from methodological and measurement differences and thus additional research using alternate manipulations and/or a variety of maturity/masculinity measurements may be beneficial for clarification. Alternatively, the lack of corroboration here may be indicative of a global rather than rooted mating context effect. That is, in Pettijohn and Tesser's study, participants were more ambiguously asked to select a female partner to work with rather than directly asked to select faces they considered as most attractive. Therefore, perhaps the preference for more mature looking females is a global preference for alliances with more masculine individuals but does not override typical male preference for female facial femininity (e.g., Perrett et al. 1998; Rhodes 2006).

When it comes to female mate preferences, there was a significant effect of environmental security on preference for muscle mass, whereby participants primed to believe that they would be in contact with a poisonous snake selected male body types that were significantly higher in muscle mass than those without this prime. There has been little previous research investigating the effect of experimentally induced environmental cues on body composition preferences among women, with the few studies available in this area reporting null findings for women's preference for larger/heavier men (i.e., Nelson and Morrison 2005; Pettijohn et al. 2009). However, such previous research has typically focused only on preference for body fat or for ambiguous "weight" which would, in principle, incorporate both muscle and fat. To the authors' knowledge, no experimental study to date in the ESH literature has measured preference for muscle mass. Therefore, these findings provide a novel insight into the influence of environmental threat cues on female mate preference and perhaps highlight the significance of muscle mass, specifically, rather than generic body size. This finding is also somewhat supportive of cross-cultural findings for preference for the trait of "physical strength" in economically divergent countries (e.g., Pearce et al. 2010) insofar as greater muscle mass is typically indicative of greater physical strength. More so, by applying an experimental manipulation, the finding expands on the cross-cultural methodology by suggesting that there may well be a temporal effect of threat cues rather than, or in addition to, long-term exposure to threat cues. Moreover, this finding is comparable to correlational research on selfreported safety concerns. For example, in three studies, Snyder et al. (2011) found that women's fear of crime (current or childhood) predicts preferences for long-term mates who are aggressively dominant and physically formidable. However, whereas Snyder et al.'s experimental threat prime using images of gangs and crime (study 3 ) failed to produce a shift in preference, our manipulation was successful. This may suggest that perhaps threats need to be more direct (i.e., belief that they will handle a poisonous snake rather than viewing photographs) to activate self-protection motives and subsequent changes to attitudes and preferences.

Results also suggest that environmental security impacts female preferences for facial masculinity, whereby participants who were exposed to an environmental threat prime selected male faces that were significantly more masculine in both shape and coloration contrast (i.e., lighter eyes and lips relative to skin tone) than those not exposed to a threat prime. These findings are consistent with previous research suggesting that priming pathogen concerns was associated with a stronger attraction to more masculine male faces than priming financial security concerns (Watkins et al. 2012). Given that facial masculinity in men has been 
suggested to act as a cue for physical strength (Fink et al. 2007) and dominance (Perrett et al. 1998), an increased preference for masculine men among women after an environmental threat cue could be interpreted as a facultative response to promote her own survival. In other words, a greater attraction to males who might be better able to deal with environmental threats would be more adaptive in a more threatening environment and so a mechanism to shift mate preference in response to a safety threat cue could very well have evolved to promote adaptive, context-dependent mate selection.

Results also suggest an effect of an environmental threat prime on women's mating strategies, insofar as women who were primed to believe that they would be in contact with a poisonous snake reported more positive attitudes toward short-term mating scenarios than women who did not receive this prime. However, there was no significant effect of experimental condition on attitudes toward long-term mating scenarios. One interpretation of this finding could be in line with the common finding that mortality salience promotes sexual interest (e.g., Lam et al. 2009; Taubman-Ben-Ari 2004; Taylor 2013). From an evolutionary perspective drawing on Life History theory, a safety threat promotes the idea that survival is less certain so it would be adaptive for a woman to speed up her reproductive strategy. Put another way, immediate reproductive effort becomes more adaptive than somatic effort (for future reproductive success) in less secure environments (Griskevicius et al. 2011) given the greater risk that future reproductive opportunity could be lost via death. The current study's finding for short-term mating interest expands on previous research on sexual strategy trade-offs among women in response to environmental threats such as resource scarcity (Griskevicius et al. 2011) or disease threat (Hill et al. 2015) by suggesting that an immediate safety threat can also influence reproductive strategy. The present study found more influence of this environmental cue for women than men. One possibility is that the sex ratio of participants was biased toward women. However, an alternate possibility is that, as women are limited in the number of offspring they can produce in their lifetime by the biological commitment required (e.g., 9 months of pregnancy, childbirth, up to 4 years of lactation; Trivers 1972), the adaptive costs of pursuing inappropriate mating opportunities are implicitly greater than for men and so the effective calibration of mating cognition are arguably more crucial to a woman's reproductive success. This may have led to stronger selective pressures resulting in a more context-sensitive cognitive adaptation.

The current study does have certain limitations. The sex ratio of participants was biased against men and so future research could possibly benefit from drawing a sample with a more equal ratio. Although participants in the threat condition reported significantly more fear than control participants, these means are relatively low, below the midpoint of the scale. It should therefore be acknowledged that the threat manipulation, while effective, was not particularly strong which could potentially account for some null findings. The stimuli are $3 \mathrm{D}$ digital meshes pictured in 2D and may not reflect real bodies or faces and, thus, these findings should be considered with caution. For practical reasons, the stimuli varied across only two dimensions because variation across a third dimension with five increments would have required 125 images per matrix. The dimensions included were selected as the most likely contributors to face and body sexual dimorphism based on previous research and evolutionary theory. However, future research using other relevant face and body qualities could be highly informative. For example, facial symmetry (e.g., Rhodes 2006) and perceived health (e.g., Welling et al. 2007) are important for judgments of attractiveness, and preference for these traits may be influenced by environmental threat. Also, perhaps preference for opposite dimensions in bodies as those used for male and female figures in the present study (i.e., WHR and/or body fat in male figures and WCR and/or muscle mass in female figures) or complementary combinations such as fat with muscle mass/WHR with WCR would change in response to an environmental threat cue. In addition, a potential confound with the body stimuli may arise from increasing the hip or chest width of the figures to alter WHR or WCR (respectively) while holding the waist constant, which inadvertently increases the overall perceivable mass (i.e., volume) of the figure. It is possible that this element could have had a suppressing effect on a potential WHR/WCR finding, and so future research could potentially benefit from incorporating some sort of correction to the perceivable mass of the figures. Finally, the present study incorporated an element of sexual strategy by freely measuring attitudinal indicators of sociosexual orientation (i.e., STMO and LTMO). However, given the inherent relationship between sexual strategy and mate preferences whereby both men and women tend to show a different pattern of mate preferences in a long-term versus short-term mating context (e.g., Kenrick et al. 1993; Mogilski et al. 2014; Stewart et al. 2000; Swami et al. 2008), it could be fruitful to define mating context prior to the evaluation of stimuli to further investigate preferences as a function of sexual strategy.

Overall, the findings from the present study are predominantly supportive of the ESH and a contextdependent model of mate preferences. By using an alternate manipulation of environmental security threat (i.e., anticipation of handling a poisonous snake), the current findings expand on the broader conceptualization of the $\mathrm{ESH}$, suggesting that mate preferences and potentially mate choice could depend on the immediate environment. Whereas previous research has used manipulations/ predictors such as resource scarcity cues and pathogen prevalence primes, the present study used a direct personal safety cue, which could explain the slightly different 
pattern of significant results than reported previously. Indeed, the present study failed to find a significant result for male preference for female face shape. However, the results from slightly different bodies of literature under the context-dependent mate preference umbrella seem to differ in their direction, with research considering resource scarcity cues (e.g., economic conditions across time) reporting a male preference for more masculine facial qualities in women during harsher conditions (Pettijohn and Jungeberg 2004; Pettijohn and Tesser 1999), whereas research on pathogen cues/concerns often report a greater male preference for more feminine facial qualities in women (Jones et al. 2013; Lee et al. 2012; Little et al. 2011; Watkins et al. 2012). Therefore, it may be possible that the cognitive mechanisms that adjust mate preferences in response to cues of environmental security are specialized, whereby different cues (e.g., safety threat, pathogen threat, and resource availability threat) may result in slightly different shifts in preferences. Future research using an array of different manipulations and/or predictors may therefore be beneficial to clarify these potential subtle differences further.

\section{Compliance with ethical standards}

Conflict of interest The authors declare that they have no conflict of interest.

Ethical approval All procedures performed in studies involving human participants were in accordance with the ethical standards of the institutional and/or national research committee and with the 1964 Helsinki Declaration and its later amendments or comparable ethical standards.

Informed consent Informed consent was obtained from all individual participants included in the study.

\section{References}

Archer, J. (2006). Testosterone and human aggression: an evaluation of the challenge hypothesis. Neuroscience \& Biobehavioral Reviews, 30(3), 319-345.

Bargh, J. A., \& Chartrand, T. L. (2000). The mind in the middle: a practical guide to priming and automaticity research. In H. T. Reis \& C. M. Judd (Eds.), Handbook of research methods in social and personality psychology (pp. 253-285). New York, NY, US: Cambridge University Press.

Bateup, H. S., Booth, A., Shirtcliff, E. A., \& Granger, D. A. (2002). Testosterone, cortisol, and women's competition. Evolution and Human Behavior, 23, 181-92.

Biro, F. M., Lucky, A. W., Simbartl, L. A., Barton, B. A., Daniels, S. R., Striegel-Moore, R., Kronsberg, S. S., \& Morrison, J. A. (2003). Pubertal maturation in girls and the relationship to anthropometric changes: pathways through puberty. The Journal of Pediatrics, $142(6), 643-646$
Booth, A., \& Dabbs, J. (1993). Testosterone and men's marriages. Social Forces, 72, 463-477.

Boothroyd, L. G., Jones, B. C., Burt, D., Cornwell, R., Little, A. C., Tiddeman, B. P., \& Perrett, D. I. (2005). Facial masculinity is related to perceived age but not perceived health. Evolution and Human Behavior, 26(5), 417-431.

Copeland, J. L., Consitt, L. A., \& Tremblay, M. S. (2002). Hormonal responses to endurance and resistance exercise in females aged 19-69 years. The Journals of Gerontology Series A: Biological Sciences and Medical Sciences, 57(4), B158-B165.

DeBruine, L. M., Jones, B. C., Crawford, J. R., Welling, L. L. M., \& Little, A. C. (2010). The health of a nation predicts their mate preferences: cross-cultural variation in women's preferences for masculinized male faces. Proceedings of the Royal Society of London B, 277(1692), 2405-2410.

DeBruine, L. M., Jones, B. C., Little, A. C., Crawford, J. R., \& Welling, L. L. M. (2011). Further evidence for regional variation in women's masculinity preferences. Proceedings of the Royal Society of London B, 278, 813-814.

Evans, R. B. (1972). Physical and biochemical characteristics of homosexual men. Journal of Consulting and Clinical Psychology, 39(1), $140-147$.

Fink, B., Neave, N., \& Seydel, H. (2007). Male facial appearance signals physical strength to women. American Journal of Human Biology, 19(1), 82-87.

Folland, J. P., \& Williams, A. G. (2007). Morphological and neurological contributions to increased strength. Sports Medicine, 37(2), 145168.

Folstad, I., \& Karter, A. J. (1992). Parasites, bright males, and the immunocompetence handicap. American Naturalist, 139, 603-622.

Frayer, D. W., \& Wolpoff, M. H. (1985). Sexual dimorphism. Annual Review of Anthropology, 14, 429-473.

Gatford, K. L., Egan, A. R., Clarke, I. J., \& Owens, P. C. (1998). Sexual dimorphism of the somatotrophic axis. Journal of Endocrinology, 157(3), 373-389.

Griskevicius, V., Delton, A. W., Robertson, T. E., \& Tybur, J. M. (2011). Environmental contingency in life history strategies: the influence of mortality and socioeconomic status on reproductive timing. Journal of Personality and Social Psychology, 100(2), 241-255.

He, Q., Horlick, M., Thornton, J., Wang, J., Pierson, R. N., Heshka, S., \& Gallagher, D. (2004). Sex-specific fat distribution is not linear across pubertal groups in a multiethnic study. Obesity Research, 12(4), 725-733.

Hill, S. E., Prokosch, M. L., \& DelPriore, D. J. (2015). The impact of perceived disease threat on women's desire for novel dating and sexual partners: is variety the best medicine? Journal of Personality and Social Psychology, 109(2), 244-261.

Isbell, L. A. (2006). Snakes as agents of evolutionary change in primate brains. Journal of Human Evolution, 51(1), 1-35.

Jackson, J. J., \& Kirkpatrick, L. A. (2007). The structure and measurement of human mating strategies: toward a multidimensional model of sociosexuality. Evolution and Human Behavior, 28(6), 382-391.

Jasieńska, G., \& Ellison, P. T. (1998). Physical work causes suppression of ovarian function in women. Proceedings of the Royal Society of London B: Biological Sciences, 265(1408), 1847-1851.

Jasienska, G., Ziomkiewicz, A., Ellison, P. T., Lipson, S. F., \& Thune, I. (2004). Large breasts and narrow waists indicate high reproductive potential in women. Proceedings of the Royal Society of London: Biological Sciences, 271, 1213-1217.

Jasienska, G., Ziomkiewicz, A., Thune, I., Lipson, S. F., \& Ellison, P. T. (2006). Habitual physical activity and estradiol levels in women of reproductive age. European Journal of Cancer Prevention, 15(5), 439-445.

John, O. P., \& Srivastava, S. (1999). The Big Five trait taxonomy: history, measurement, and theoretical perspectives. Handbook of personality: Theory and Research, 2, 102-138. 
Johnston, V. S. (2000). Female facial beauty: the fertility hypothesis. Pragmatics \& Cognition, 8(1), 107-122.

Johnston, V. S., Hagel, R., Franklin, M., Fink, B., \& Grammer, K. (2001). Male facial attractiveness: evidence for hormone-mediated adaptive design. Evolution and Human Behavior, 22(4), 251-267.

Jones, D. (1995). Sexual selection, physical attractiveness, and facial neoteny. Current Anthropology, 36, 723-748.

Jones, B. C., Feinberg, D. R., Watkins, C. D., Fincher, C. L., Little, A. C., \& DeBruine, L. M. (2013). Pathogen disgust predicts women's preferences for masculinity in men's voices, faces, and bodies. Behavioral Ecology, 24(2), 373-379.

Kasperk, C., Helmboldt, A., Borcsok, I., Heuthe, S., Cloos, O., Niethard, F., \& Ziegler, R. (1997). Skeletal site-dependent expression of the androgen receptor in human osteoblastic cell populations. Calcified Tissue International, 61(6), 464-473.

Keizer, H. A., Kuipers, H., De Haan, J., Beckers, E., \& Habets, L. (1987). Multiple hormonal responses to physical exercise in eumenorrheic trained and untrained women. International Journal of Sports Medicine, 8, 139-150.

Kenrick, D. T., Groth, G. E., Trost, M. R., \& Sadalla, E. K. (1993). Integrating evolutionary and social exchange perspectives on relationships: effects of gender, self-appraisal, and involvement level on mate selection criteria. Journal of Personality and Social Psychology, 64, 951-969.

Kirchengast, S. (2010). Gender differences in body composition from childhood to old age: an evolutionary point of view. Journal of Life Science, 2(1), 1-10.

Kuoppasalmi, K., Näveri, H., Rehunen, S., Härkönen, M., \& Adlercreutz, H. (1976). Effect of strenuous anaerobic running exercise on plasma growth hormone, cortisol, luteinizing hormone, testosterone, androstenedione, estrone and estradiol. Journal of Steroid Biochemistry, 7(10), 823-829.

Lam, S. R., Morrison, K. R., \& Smeesters, D. (2009). Gender, intimacy, and risky sex: a terror management account. Personality and Social Psychology Bulletin, 35(8), 1046-1056.

Lavranos, G., Angelopoulou, R., Manolakou, P., \& Balla, M. (2006). Hormonal and meta-hormonal determinants of sexual dimorphism. Collegium Antropologicum, 30(3), 659-663.

Law Smith, M. J., Perrett, D. I., Jones, B. C., Cornwell, R. E., Moore, F. R., Feinberg, D. R., Boothroyd, L. G., Durrani, S. J., Stirrat, M. R., Whiten, S., Pitman, R. M., \& Hillier, S. G. (2006). Facial appearance is a cue to oestrogen levels in women. Proceedings of the Royal Society of London Series B, 273, 135-140.

Lee, A. J., Dubbs, S. L., Kelly, A. J., von Hippel, W., Brooks, R. C., \& Zietsch, B. P. (2012). Human facial attributes, but not perceived intelligence, are used as cues of health and resource provision potential. Behavioral Ecology, 24(3), 779-787.

Little, A. C., DeBruine, L. M., \& Jones, B. C. (2011). Exposure to visual cues of pathogen contagion changes preferences for masculinity and symmetry in opposite-sex faces. Proceedings of the Royal Society of London B: Biological Sciences, 278(1714), 2032-2039.

Loomba-Albrecht, L. A., \& Styne, D. M. (2009). Effect of puberty on body composition. Current Opinion in Endocrinology, Diabetes, and Obesity, 16(1), 10-15.

Manning, J. T., Koukourakis, K., \& Brodie, D. A. (1997). Fluctuating asymmetry, metabolic rate and sexual selection in human males. Evolution and Human Behavior, 18, 15-21.

McIntyre, M., Gangestad, S. W., Gray, P. B., Chapman, J. F., Burnham, T. C., O'Rourke, M. T., \& Thornhill, R. (2006). Romantic involvement often reduces men's testosterone levels - but not always: the moderating role of extrapair sexual interest. Journal of Personality and Social Psychology, 91(4), 642.

Mittendorfer, B. (2005). Sexual dimorphism in human lipid metabolism. The Journal of Nutrition, 135(4), 681-686.
Mogilski, J., Wade, T. J., \& Welling, L. L. M. (2014). Prioritization of potential mates' history of sexual fidelity during a conjoint ranking task. Personality and Social Psychology Bulletin, 40(7), 884-889.

Molarius, A., Seidell, J. C., Sans, S., Tuomilehto, J., \& Kuulasmaa, K. (1999). Waist and hip circumferences, and waist-hip ratio in 19 populations of the WHO MONICA Project. International journal of obesity and related metabolic disorders: journal of the International Association for the Study of Obesity, 23(2), 116-125.

Nelson, L. D., \& Morrison, E. L. (2005). The symptoms of resource scarcity: judgements of food and finances influence preferences for potential partners. Psychological Science, 16, 167-173.

Öhman, A., \& Mineka, S. (2001). Fears, phobias, and preparedness: toward an evolved module of fear and fear learning. Psychological Review, 108(3), 483.

Pearce, A. R., Chuikova, T., Ramsey, A., \& Galyautdinova, S. (2010). A positive psychology perspective on mate preferences in the United States and Russia. Journal of Cross-Cultural Psychology, 41(5-6), 742-757.

Penton-Voak, I. S., Jacobson, A. A., \& Trivers, R. R. (2004). Populational differences in attractiveness judgments of male and female faces: comparing British and Jamaican samples. Evolution and Human Behavior, 25(6), 355-370.

Perrett, D. I., Lee, K. J., Penton-Voak, I. S., Rowland, D. R., Yoshikawa, S., Burt, D. M., Henzi, S. P., Castles, D. L., \& Akamatsu, S. (1998). Effects of sexual dimorphism on facial attractiveness. Nature, 394, 884-887.

Peters, M., Simmons, L. W., \& Rhodes, G. (2008). Testosterone is associated with mating success but not attractiveness or masculinity in human males. Animal Behaviour, 76(2), 297-303.

Pettijohn, T. F., \& Jungeberg, B. J. (2004). Playboy playmate curves: changes in facial and body feature preferences across social and economic conditions.Personality and. Social Psychology Bulletin, 30(9), 1186-1197.

Pettijohn, T. F., \& Tesser, A. (1999). Popularity in environmental context: facial feature assessment of American movie actresses. Media Psychology, 1(3), 229-247.

Pettijohn, T. F., \& Tesser, A. (2003). History and facial features: the eyes have it for actresses but not for actors. North American Journal of Psychology, 5(3), 335-343.

Pettijohn, T. F., \& Tesser, A. (2005). Threat and social choice: when eye size matters. The Journal of Social Psychology, 145(5), 547-570.

Pettijohn, T. F., II, Sacco, D. F., \& Yerkes, M. J. (2009). Hungry people prefer more mature mates: a field test of the environmental security hypothesis. Journal of Social, Evolutionary, and Cultural Psycholog, 3(3), 216.

Price, T. M., O'Brien, S. N., Welter, B. H., George, R., Anandjiwala, J., \& Kilgore, M. (1998). Estrogen regulation of adipose tissue lipoprotein lipase - possible mechanism of body fat distribution. American Journal of Obstetrics and Gynecology, 178(1), 101-107.

Refubbe-Scrieve, M. (1988). Metabolic differences in fat deposits. In C. Bourchard \& F. E. Johnston (Eds.), Fat distribution during growth and later health outcomes (pp. 163-173). New York: Alan R. Liss.

Reubinoff, B. E., Wurtman, J., Rojansky, N., Adler, D., Stein, P., Schenker, J. G., \& Brzezinski, A. (1995). Effects of hormone replacement therapy on weight, body composition, fat distribution, and food intake in early postmenopausal women: a prospective study. Fertility \& Sterility, 64(5), 963-968.

Rhodes, G. (2006). The evolutionary psychology of facial beauty. Annual Review of Psychology, 57, 199-226.

Rogol, A. D., Roemmich, J. N., \& Clark, P. A. (2002). Growth at Puberty. Journal of Adolescent Health, 31, 192-200.

Rosenbaum, M., \& Leibel, R. L. (1999). Clinical review 107: role of gonadal steroids in the sexual dimorphisms in body composition and circulating concentrations of leptin. The Journal of Clinical Endocrinology and Metabolism, 84(6), 1784-1789. 
Rowland, D., \& Perrett, D. (1995). Manipulating facial appearance through shape and color. Computer Graphics and Applications, IEEE, 15(5), 70-76.

Russell, R. (2003). Sex, beauty, and the relative luminance of facial features. Perception, 32(9), 1093-1107.

Ruys, K. I., \& Stapel, D. A. (2008). How to heat up from the cold: examining the preconditions for (unconscious) mood effects. Journal of Personality and Social Psychology, 94, 777-791.

Sacco, D. F., Young, S. G., Brown, C. M., Bernstein, M. J., \& Hugenberg, K. (2011). Social exclusion and female mating behavior: rejected women show strategic enhancement of short-term mating interest. Evolutionary Psychology, 10(3), 573-587.

Shibasaki, M., \& Kawai, N. (2009). Rapid detection of snakes by Japanese monkeys (Macaca fuscata): an evolutionarily predisposed visual system. Journal of Comparative Psychology, 123(2), 131.

Singh, D. (1995). Female judgment of male attractiveness for relationships: role of waist-to-hip ratio and financial status. Journal of Personality and Social Psychology, 69(6), 1089-1101.

Snyder, J. K., Fessler, D. M., Tiokhin, L., Frederick, D. A., Lee, S. W., \& Navarrete, C. D. (2011). Trade-offs in a dangerous world: women's fear of crime predicts preferences for aggressive and formidable mates. Evolution and Human Behavior, 32(2), 127-137.

Soares, S. C. (2012). The lurking snake in the grass: interference of snake stimuli in visually taxing conditions. Evolutionary Psychology, 10(2), 187.

Stewart, S., Stinnett, H., \& Rosenfeld, L. B. (2000). Sex differences in desired characteristics of short-term and long-term relationship partners. Journal of Social and Personal Relationships, 17, 843-853.

Swami, V. (2015). Cultural influences on body size ideals. European Psychologist, 20(1), 44-51.

Swami, V., \& Tovée, M. J. (2005). Female physical attractiveness in Britain and Malaysia: a cross-cultural study. Body Image, 2(2), $115-128$.

Swami, V., \& Tovée, M. J. (2006). Does hunger influence judgments of female physical attractiveness? British Journal of Psychology, 97(3), 353-363.

Swami, V., \& Tovée, M. J. (2012). The impact of psychological stress on men's judgements of female body size. PLoS ONE, 7(8), e42593.

Swami, V., Knight, D., Tovée, M. J., Davies, P., \& Furnham, A. (2007). Preferences for female body size in Britain and the South Pacific. Body Image, 4(2), 219-223.
Swami, V., Miller, R., Furnham, A., Penke, L., \& Tovée, M. J. (2008). The influence of men's sexual strategies on perceptions of women's bodily attractiveness, health and fertility. Personality and Individual Differences, 44(1), 98-107.

Symons, D. (1979) The Evolution of Human Sexuality. New York: Oxford University Press.

Tanner, J. M. (1981). Growth and maturation during adolescence. Nutrition Reviews, 39(2), 43-55.

Taubman-Ben-Ari, O. (2004). Intimacy and Risky Sexual BehaviorWhat does it have to do with Death? Death Studies, 28(9), 865-887.

Taylor, L. D. (2013). Dying to watch: thoughts of death and preferences for sexual media content. Journal of Media Psychology: Theories, Methods, and Applications, 25(2), 55-64.

Trivers, R. (1972). Parental investment and sexual selection. In B. Campbell (Ed.), Sexual selection and the descent of man (pp. 136179). New York: Aldine de Gruyter.

Volek, J. S., Kraemer, W. J., Bush, J. A., Incledon, T., \& Boetes, M. (1997). Testosterone and cortisol in relationship to dietary nutrients and resistance exercise. Journal of Applied Physiology, 82(1), 4954.

Watkins, C. D., DeBruine, L. M., Little, A. C., Feinberg, D. R., \& Jones, B. C. (2012). Priming concerns about pathogen threat versus resource scarcity: dissociable effects on women's perceptions of men's attractiveness and dominance. Behavioral Ecology and Sociobiology, 66(12), 1549-1556.

Watson, D., \& Clark, L. A. (1999). The PANAS-X: Manual for the positive and negative affect schedule-expanded form

Webb, M. L., Wallace, J. P., Hamill, C., Hodgson, J. L., \& Mashaly, M. M. (1984). Serum testosterone concentration during two hours of moderate intensity treadmill running in trained men and women. Endocrine Research, 10(1), 27-38.

Welling, L., Conway, C., Debruine, L., \& Jones, B. (2007). Perceived vulnerability to disease is positively related to the strength of preferences for apparent health in faces. Journal of Evolutionary Psychology, 5(1-4), 131-139.

Wells, J. C. (2007). Sexual dimorphism of body composition. Best Practice \& Research Clinical Endocrinology \& Metabolism, 21(3), 415-430.

Wells, J. C. (2012). Sexual dimorphism in body composition across human populations: associations with climate and proxies for shortand long-term energy supply. American Journal of Human Biology, 24(4), 411-419. 